\title{
Collection and consumption of wild forest fruits in rural Zambia
}

Amy Ickowitz', Lubomba Bwembelo², Akatama Mulani², Alice Likando Masheke Siamutondo², Penias Banda², Davison Gumbo², Kaala Moombe ${ }^{2}$ and E Ashley Steel ${ }^{3}$

\section{Key messages}

- Foods from forests are important for peoples' diets in many countries, but the amounts collected and consumed have been difficult to quantify.

- We report results from a study carried out in Zambia, in which 209 households were surveyed across all of the country's agroecological zones. Based on the results of this survey and other nationally available data, we estimate that, for surveyed households, wild fruits collected from forests contribute approximately $80 \%$ of total fruit intake.

- The reported amount of wild fruits consumed from forests would be enough, on average, to meet $25 \%$ of international recommendations on fruit intake.

- Zambians are very far from meeting nutritional recommendations on fruit consumption. If forests in Zambia were to be converted to other land uses, already poor diets could become significantly worse.

\section{Introduction}

Many people collect and consume wild foods from forests all over the world, but quantitative data on these forest products are rarely captured in national or international statistics. Where households depend on wild foods for diets, the sustainable management of the resources that supply those foods can be critical to ensure their food security. A better estimate of the quantity of foods extracted from forests, as well as the variation of collection patterns within countries, can inform management of both forestry and other land-use sectors. The degree to which those foods are consumed and have the potential to contribute to nutritious diets can also inform national nutrition programs and raise awareness of the contribution of forests to food security and nutrition.

\footnotetext{
Center for International Forestry Research, (CIFOR)

2 Center for International Forestry Research, (CIFOR)

3 Food and Agricultural Organization (FAO) of the United Nations
}

The Collaborative Partnership on Forests has developed a Global Core Set (GCS) of forest-related indicators to highlight the contributions that forests make to various international processes and agreements. This GCS consists of 21 indicators ranked from tier 1 to tier 3 (strongest to weakest) based on available data and methods. Indicator 14: "Contributions of forests and trees to food security and nutrition" is currently ranked as tier 3 because of the lack of global data and agreed methods for trying to capture this information. The contribution of wild food from forests should be an essential component of such an indicator; but information is not yet systematically collected at country level. In this brief, results are presented from a small project that can be seen as a pilot for how such information could be captured.

In 2019, CIFOR in collaboration with the Food and Agriculture Organization of the United Nations (FAO), carried out a research project to measure the collection and consumption of wild foods across Zambia. The study used a recall period of one year to capture the seasonal nature of most wild foods and an innovative method to 
ensure that household units were quantified correctly. The project was carried out in five areas covering all agroecological zones of the country. Here we present findings related to wild fruit collection and consumption across these regions.

\section{Zambia}

The 2018 Global Nutrition Report classified Zambia as a country suffering from the triple burden of malnutrition - overnutrition, undernutrition and micronutrient deficiencies. Zambian diets are reported to be relatively monotonous, consisting of large portions of maize-based staples along with a 'relish' of vegetables, and small portions of fish or meat for those who can afford them (Kaliwile et al. 2019). This is reflected in a dietary pattern characterized by heavy reliance on cereals; during 2010 2013 over half of the calories consumed by the average Zambian came from cereals (Harris et al. 2019), mostly from maize. This lack of diversity in national diets gained national attention in 2019, when the vice president urged Zambians to diversify their staple foods beyond maize and to increase their consumption of other foods for better nutrition and as a mechanism for coping with changing environmental conditions (BBC 2019).

The reported availability of nutrient-rich foods - such as fruits, vegetables and pulses - is low in Zambia, and has been declining over the last 50 years (Harris et al. 2019); however, the data used to make these calculations relies on international food supply data (FAOSTAT) which does not include wild foods. The nutritional importance of wild foods could be especially high if they are consumed in sufficient quantities to compensate for shortfalls in agricultural production or imports.

While staple foods like maize are important for calories, they generally do not deliver large quantities of important nutrients like vitamins and minerals. Nutritionists recommend that people eat a diversity of foods to ensure that they consume all of the required macro- and micronutrients in their diets. Fruits and vegetables are particularly nutrient-dense food groups, delivering not only essential micronutrients but also fiber for maintaining healthy digestion and healthy microbiomes. Diets low in fruit are one of the most significant dietary risk factors for mortality globally (Afshin et al. 2019). The World Health Organization (WHO) recommends that individuals consume a minimum of $400 \mathrm{~g}$ of fruit and vegetables per day (WHO and FAO 2002), which is often interpreted as 200 $\mathrm{g}$ of fruits and $200 \mathrm{~g}$ of vegetables, or two and a half servings of each (at approximately $80 \mathrm{~g}$ per serving)

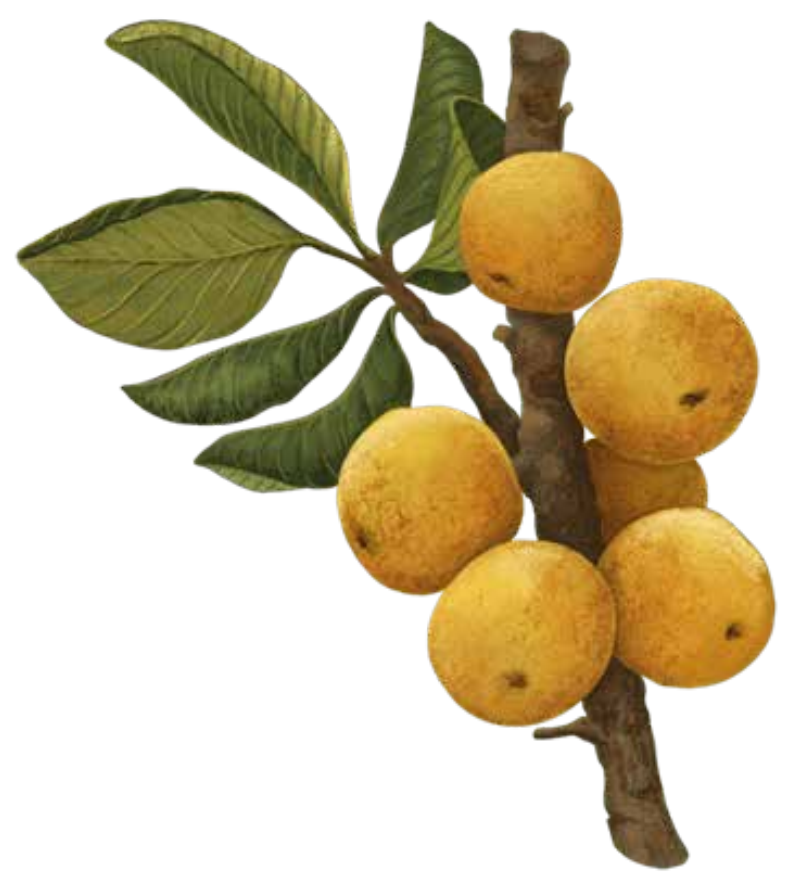

Masuku (Uapaca kirkiana), also called 'sugar plum', it is considered one of the most loved fruits in Zambia

per day, although some countries recommend a higher proportion of vegetables. The EAT Lancet reference diet suggests an average of $200 \mathrm{~g}$ of fruits a day and $300 \mathrm{~g}$ of vegetables (Willet et al. 2019). Few countries meet these minimum recommendations (Berners Lee et al. 2019) and many countries do not produce sufficient amounts of fruits and vegetables to meet national requirements (Mason-D'Croz et al. 2019).

Collection and consumption of wild foods - including fruits and vegetables - are generally not captured in national statistics, and when they are included, data are far from comprehensive (Sorrenti 2017). Evidence is emerging that in some places the contribution of wild foods could be significant, particularly in forested areas. Ickowitz et al. (2014) found that across 21 African countries, children's consumption of fruits and vegetables increased with tree cover for the vast majority of over 90,000 children under five years old, which the authors hypothesize may in part be due to wild food consumption from forests. Rowland et al. (2017) found that in forested sites across 24 countries, forest contributed up to $15 \%$ of recommended fruit and vegetable intake for the top $25 \%$ of forest users. And in Zambia, a study by FAO and the Zambia Forestry Department (2016) found that 29\% of all households collected wild fruits, nuts, seeds and tubers from forests. 


\section{The project}

The objective of the CIFOR and FAO led 'Scaling up data on non-wood forest products in Zambia' project was to quantify the collection and consumption of wild foods in the country, by looking at study areas in all agroecological zones. Project goals included piloting new methods and exploring within-country variation in both collection and consumption patterns. Five study areas were selected based on prior knowledge of the regions and good relationships with relevant authorities: Kazungula (zone 1); Choma (zone 2a); Kaoma (zone 2b); Luwingu (zone 3); and Masaiti (zone 3). Within each study area, two or three villages were selected at random, within which households were also randomly selected.

Focus group discussions were held in each study area to identify the main wild foods commonly collected. Participants were asked to rank the five most important wild foods for each of the following food types: fruit, vegetables, tubers, nuts, aquatic plants, wild meat, freshwater fish and insects. Information on the most commonly collected wild food species was then used to create a localized household survey of the annual collected volume and proportion consumed of the top five locally-identified wild foods for each food type. Here, we focus on the collection and consumption of wild fruits due to the availability of global dietary recommendations on intake, as well as previous national data for comparison.

A total of 209 household surveys were carried out in 14 villages, with the female heads of households targeted as the primary respondents, since women are the primary collectors of most of the food types (except for meat and fish). Male respondents were often also present. Respondents were also given a food frequency questionnaire in which they were asked how many times, in the week preceding the survey, they ate various foods commonly consumed in their region, both cultivated and wild. The food frequency questionnaire allowed us to capture some information about the whole

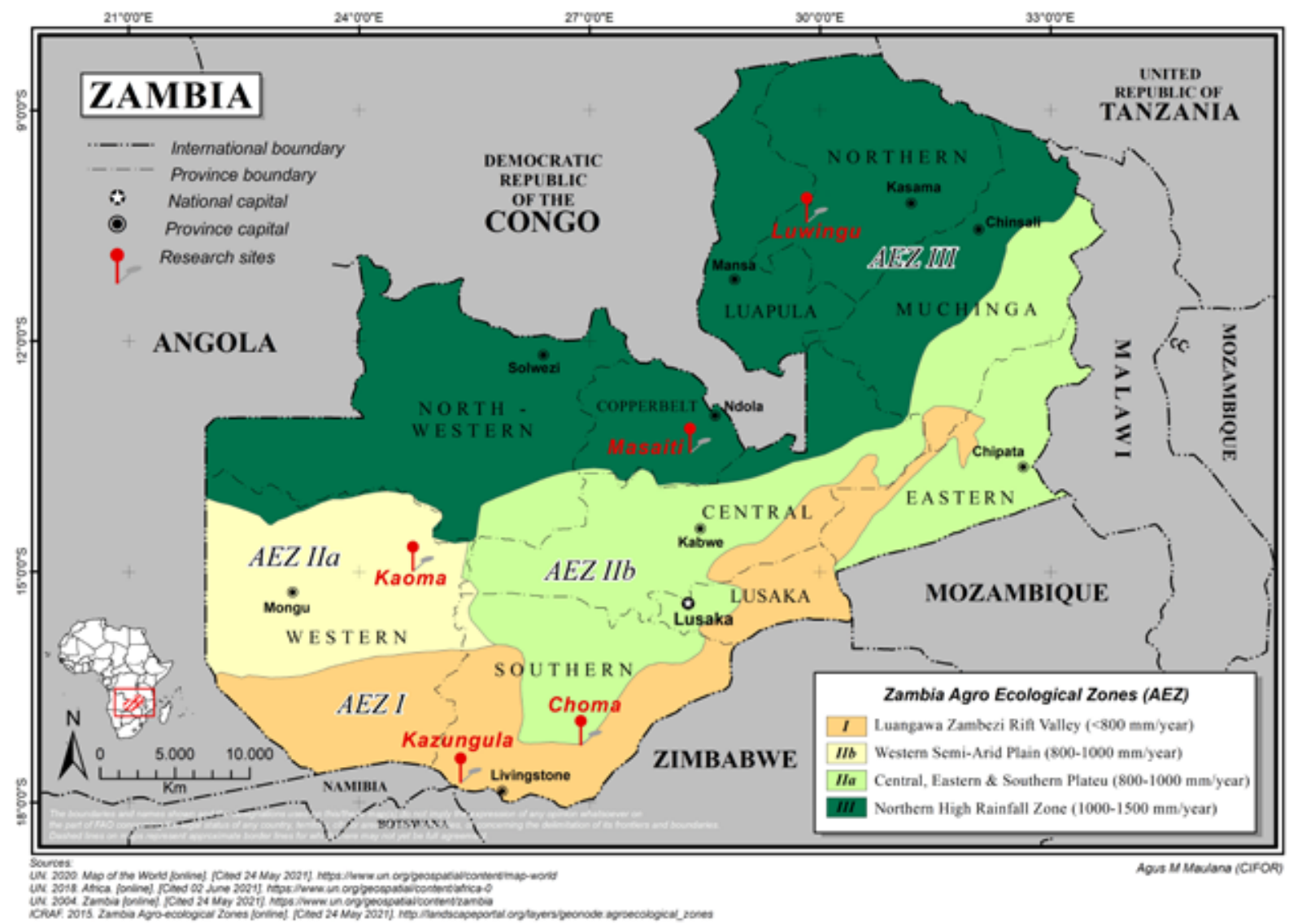

Figure 1. Map of Zambia's agroecological zones, with pins showing the five areas where the project was carried out Note: The boundaries and names shown and the designations used on this/these map(s) do not imply the expression of any opinion whatsoever on the part of FAO concerning the legal status of any country, territory, city or area or of its authorities, or concerning the delimitation of its frontiers and boundaries. Dashed lines on maps represent approximate border lines for which there may not yet be full agreement. 
diet (not just wild foods), and also had the advantage of a shorter recall window. The two sources of information were analyzed to create a picture of the contributions that wild foods make to local diets and of how this might differ across sites.

All results are presented with estimates of uncertainty due to variability across households. Additional uncertainties which could not be quantified include: (a) the selection of study areas where CIFOR already had a working relationship, which are more likely to be forest-dependent communities which could result in an overestimate of the amount of wild foods collected and consumed; (b) recall error (unknown direction of bias); (c) the survey was conducted during the dry season so that the one-week recall may have contained fewer wild foods than it might have at other times; (d) the study did not capture fruits that are eaten 'casually', e.g. fruits collected and eaten by other members of the household, especially children, resulting in an underestimate of quantities collected and consumed; and (e) collection of data for only the five most commonly collected species in each product type in each study area resulting in an underestimate of total wild food collection and consumption.

\section{Results}

\section{Fruit collection}

As can be seen in Figure 2, fruit was almost universally collected, but the volume varied markedly across sites and also across households within sites. The quantities were substantial, with some households estimated to collect over 1000 liters $(L)$ of fruit every year.

During the focus group discussions, participants identified 14 commonly consumed wild fruits across all sites (Table 1). None of the fruit species were collected at all five sites, or even at four of the sites. Only three species were collected at three of the sites, and four fruits were unique to a particular site.

\section{Fruit consumption}

The vast majority of fruit collected - 98\% - was consumed rather than sold. Reported quantities consumed were divided by adult male equivalents to estimate quantities consumed per individual ${ }^{4}$.

4 Converting to 'adult male equivalents' is a way to convert dietary requirements for everyone in the household to the same units since children and women have different nutritional requirements. Conversion factors using table from: https://www.springnutrition.org/ sites/default/files/spring_presentation_hces_tool_sununtnasuk.pdf

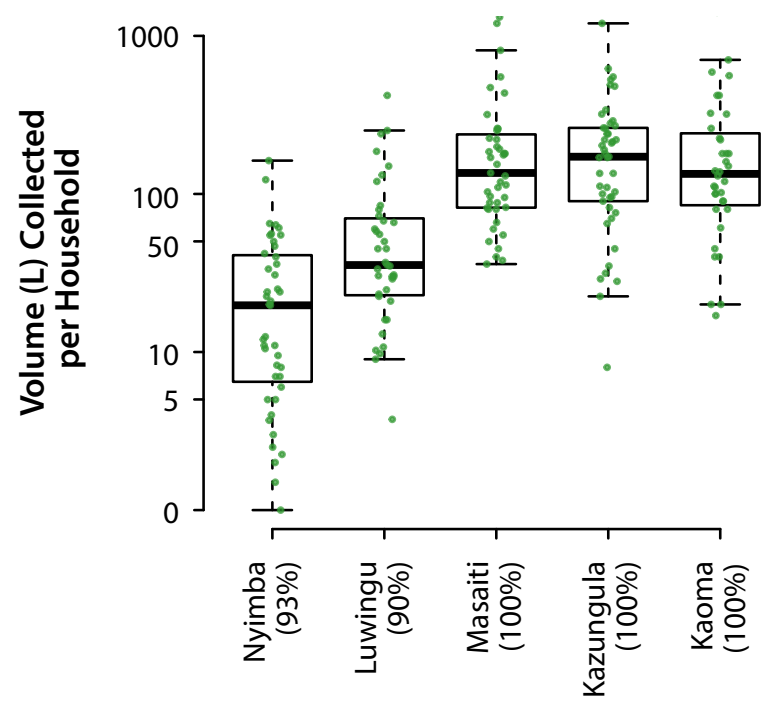

Figure 2. Volumes in liters (L) of wild fruit collected per household in each study area for those households collecting wild fruits; the percentages along the bottom axis indicate the percentage of surveyed houses in each study area that collect wild fruits. The top five species of wild fruit collected in each study area are indicated in Table 1.

Note: The $y$-axis is on a log scale but labeled in original units for ease of interpretation

In the year preceding the survey, households across the five sites collected and consumed approximately $122.5 \mathrm{~kg}$ of wild fruit, or $29.8 \mathrm{~kg}$ per person. In order to compare this with the World Health Organization's recommendation of $200 \mathrm{~g}$ of fruit per day, we converted each of the fruits to 'edible' quantities by calculating the proportion of weight that is actually consumed (i.e. subtracting the weight of peel, seeds, etc.). As information was not available on edible portion weight for all of the reported fruits, we used all the published information that we could locate, weighed the fruits that were available in the local market for which there were no data, and estimated the amounts for the other fruits based on local expert knowledge. Average edible weight of wild fruit consumed was calculated at $16.5 \mathrm{~kg}$ per person over the course of the year.

We compared this data with a nationally representative survey, 'Zambia STEPS for Noncommunicable Disease Risk Factors', conducted by the Zambian Ministry of Health in 2017. Among the survey questions was a series on frequency and approximate portion size of fruits and vegetables. The study found that, on average, Zambians consumed $70 \%$ of a serving size of fruit per day. Using a standard average serving size of 80 $\mathrm{g}$, this equates to $56 \mathrm{~g}$ of fruits per day - far below the WHO recommendation and EAT reference diet of $200 \mathrm{~g}$. Figure 3 compares our findings on wild fruit with the recommended and national average. 
Table 1. Wild fruit species collected across study areas. Over $95 \%$ of all fruits were collected in forested areas across all five study areas

\begin{tabular}{|c|c|c|c|c|c|c|c|}
\hline \multirow{2}{*}{$\begin{array}{l}\text { Most common } \\
\text { local name } \\
\text { (English } \\
\text { name where } \\
\text { available) }\end{array}$} & \multirow[b]{2}{*}{ Scientific name } & \multicolumn{6}{|c|}{ Number of households collecting } \\
\hline & & Nyimba & Luwingu & Masaiti & Kazungula & Kaoma & Total \\
\hline $\begin{array}{l}\text { Masau } \\
\text { (Jujube plum) }\end{array}$ & Ziziphus mauritiana & 16 & & & & & 16 \\
\hline Mbuyu (Baobab) & Adansonia digitata & 24 & & & 30 & & 54 \\
\hline $\begin{array}{l}\text { Mchenja } \\
\text { (Jackalberry) }\end{array}$ & Diospyros mespiliformis & 22 & & & 41 & & 63 \\
\hline $\begin{array}{l}\text { Ngaingai } \\
\text { (African medlar) }\end{array}$ & Vangueria infausta & 39 & & & & & 39 \\
\hline Nkondokondo & Flacourtia indica & 28 & & & & & 28 \\
\hline $\begin{array}{l}\text { Mawi } \\
\text { (Monkey orange) }\end{array}$ & Strychnos cocculoides & & 32 & 40 & 45 & & 117 \\
\hline $\begin{array}{l}\text { Mpundu } \\
\text { (Mobola plum) }\end{array}$ & Parinari curatellifolia & & 26 & 40 & & 30 & 96 \\
\hline Nfungo & Anisophyllea boehmii & & 38 & 24 & & & 62 \\
\hline Ntungulu & Afromum africanum & & 19 & 42 & & & 61 \\
\hline $\begin{array}{l}\text { Masuku } \\
\text { (Wild loquat) }\end{array}$ & Uapaca kirkiana & & 31 & 40 & & 27 & 98 \\
\hline Nji (Bird plum) & Berchemia discolor & & & & 43 & & 43 \\
\hline Nsumo & Vangueriopsis lanciflor & & & & 43 & 25 & 68 \\
\hline Mawawa & Strychnos pungens & & & & & 35 & 35 \\
\hline Muhamani & Dialium engleranum & & & & & 26 & 26 \\
\hline
\end{tabular}

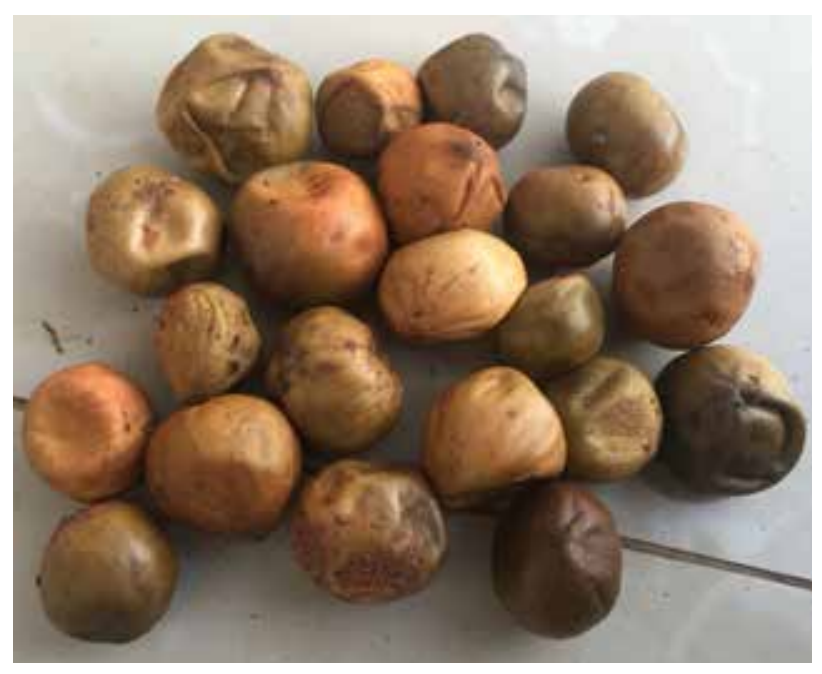

Ngai-ngai (Vangueria infausta)

Photo: E Ashley Steel/FAO

Intungulu (Afromum africanum) Photos: Lubomba Bwembelo/CIFOR

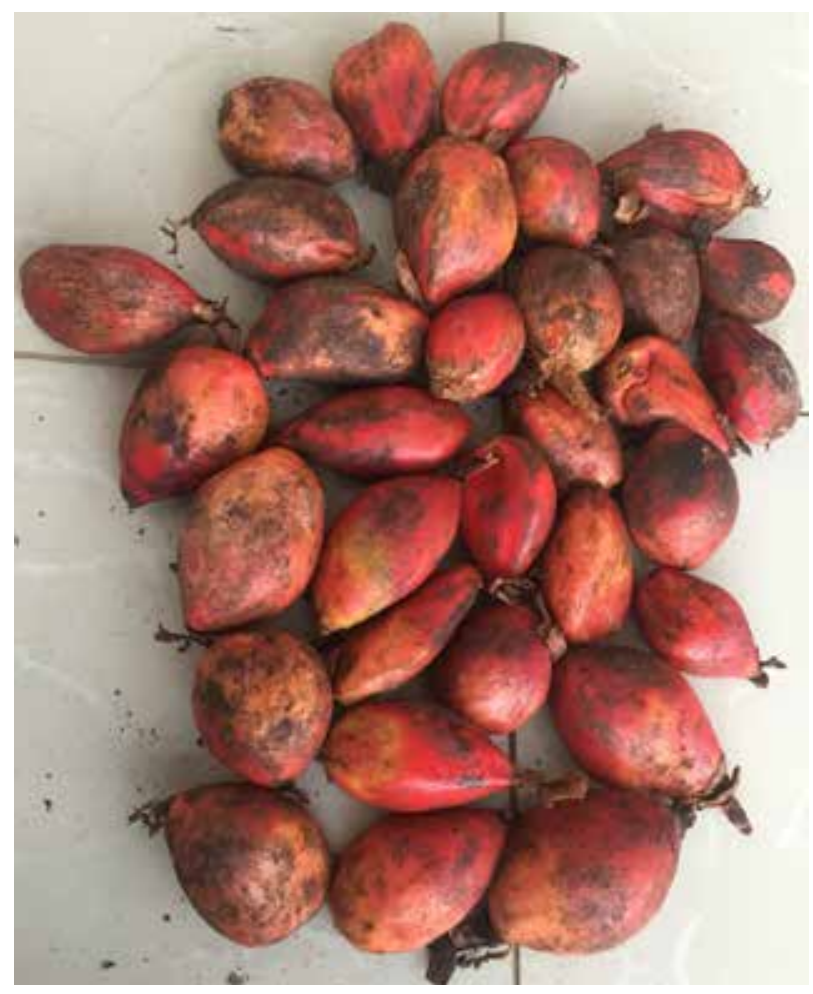




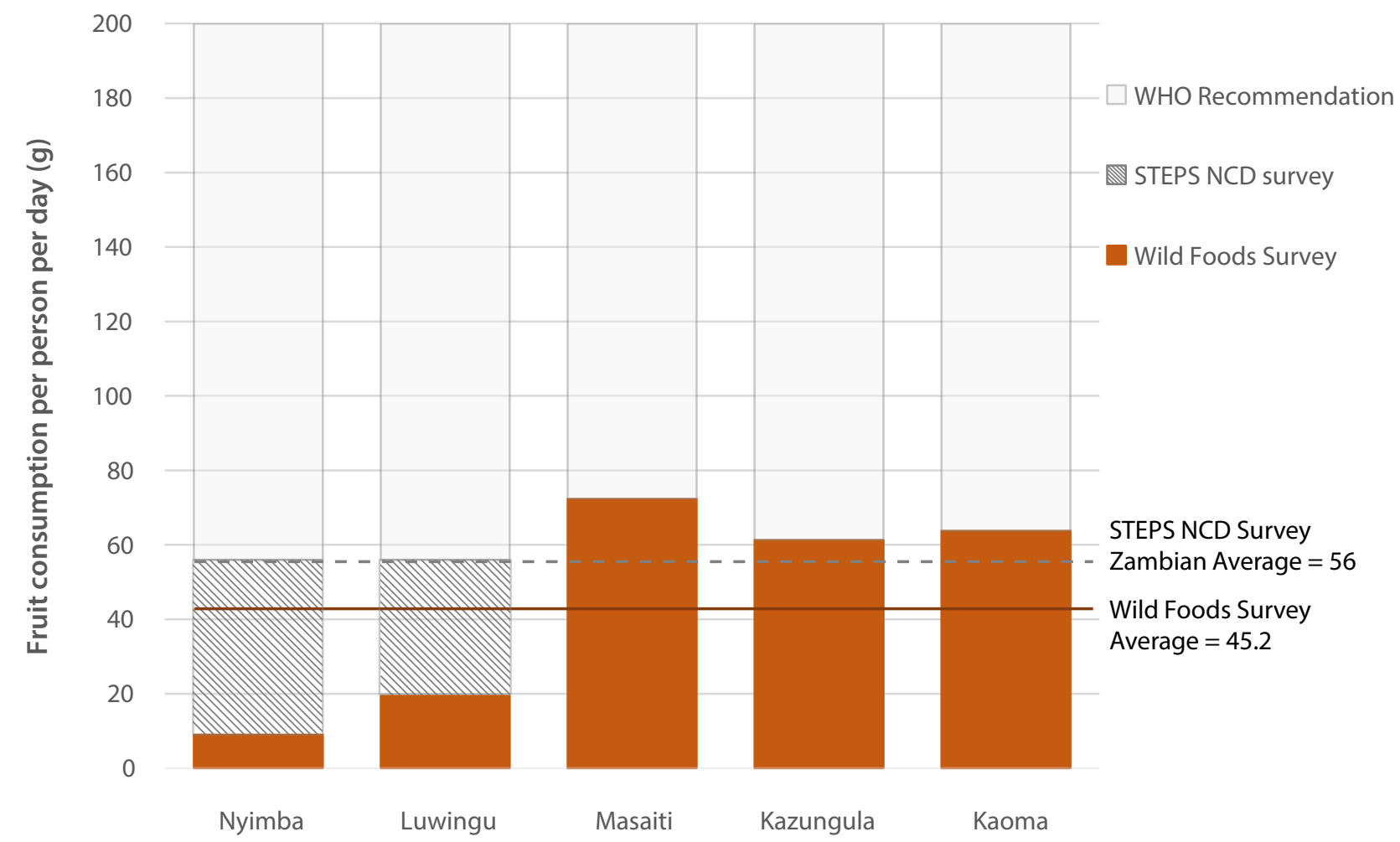

Figure 3. Comparison of WHO recommendations with fruit consumption noted in the 'Zambia STEPS for Noncommunicable Disease Risk Factors' study and wild fruit consumption as noted in this project

These results show the considerable contribution wild fruit makes to current fruit intake in rural Zambia. If the national results for fruit consumption are similar to those in the study sites, wild fruits contribute about $80 \%$ to actual fruit intake across the sites - and almost $25 \%$ of the recommended fruit intake for healthy diets. Results from the seven-day food frequency data revealed a similar qualitative pattern to the annual data on wild food collection. Note that these data were collected using a different method, focused on individual consumption (as opposed to household), with a different window of time (7 days compared to one year), and looked at frequency rather than amount. Based on this data, only $58 \%$ of women consumed any fruit in the week preceding the survey, with just 11\% having had fruit at least once a day on average. For the $42 \%$ of women consuming any fruit, wild fruit was consumed more than twice as frequently as domestic fruit (3.4 times versus 1.6 times per week). We saw large variability across sites, with fruit consumed an average of 1.3 times per week in Nyimba compared to 4.3 times per week in Masaiti. The seven-day frequency data have the advantage of better recall compared to a one-year period, however, in contrast to the annual data, they also reflect the season in which the questions were asked.

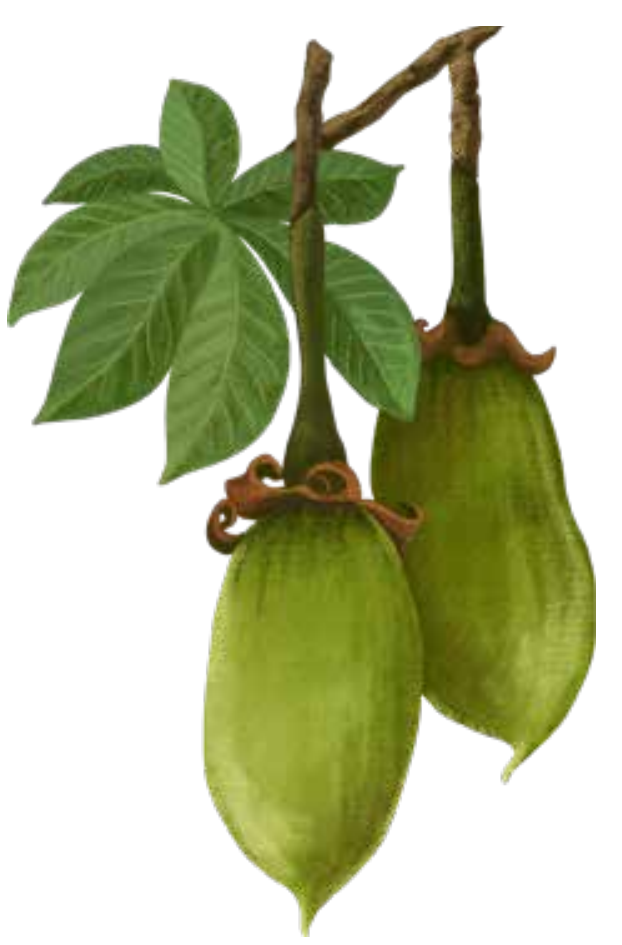

Baobab (Adansonia digitata), known as the 'tree of life', some baobabs can survive over 2,000 years 


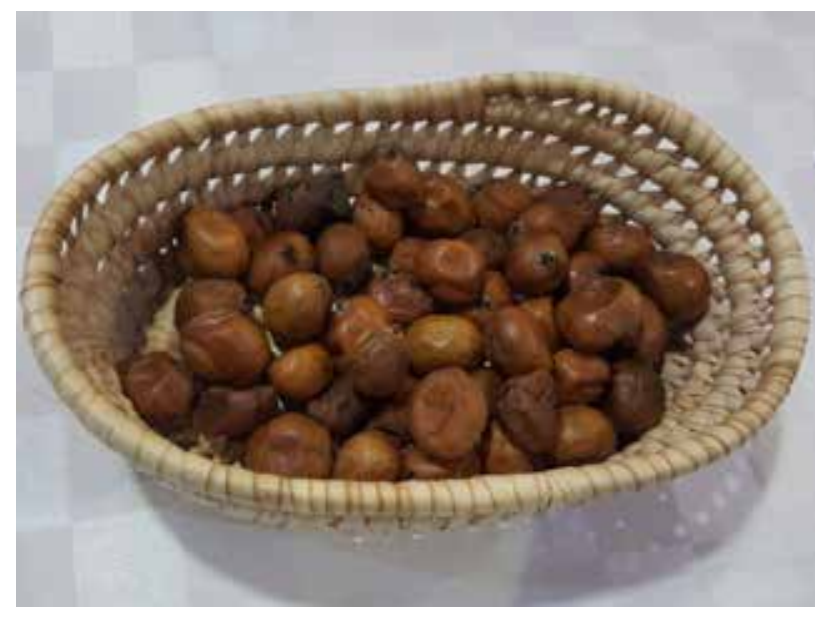

Nsumo (Vangueriopsis lanciflora)

Photo: E Ashley Steel/FAO

\section{Capturing the importance of wild foods in national and international forestry statistics and in national food composition tables}

It is often supposed that collecting quantitative data on wild foods is difficult and time-consuming. We found, by contrast, that the survey was relatively easy to administer and was short compared with many national surveys (taking an average of only 46 minutes per household to complete). Because we measured households' collecting containers, our method was able to address the problem of non-standardized measurement units, which can often present problems of quantification for these types of studies. A similar study, pairing focus groups and household surveys, administered over a larger number of nationally-representative households, would provide extremely valuable information.

The results presented here indicate the large contributions that wild fruit can make to diets and the importance of forests in supporting food and nutrition security at least in some communities. If forests in Zambia were to disappear, the impacts on diets could be devastating. Similarly, forest management that promotes reforestation and restoration, including food trees or land access provisions, could improve diets particularly for rural people. Improved quantification of the collection and consumption of wild foods can contribute to global reporting (such as the Global Core Set of Forest-related Indicators), as well as strengthen forest management and conservation within Zambia by highlighting how important forests are not only for biodiversity, climate change mitigation, energy and timber, but also for food and nutrition security.

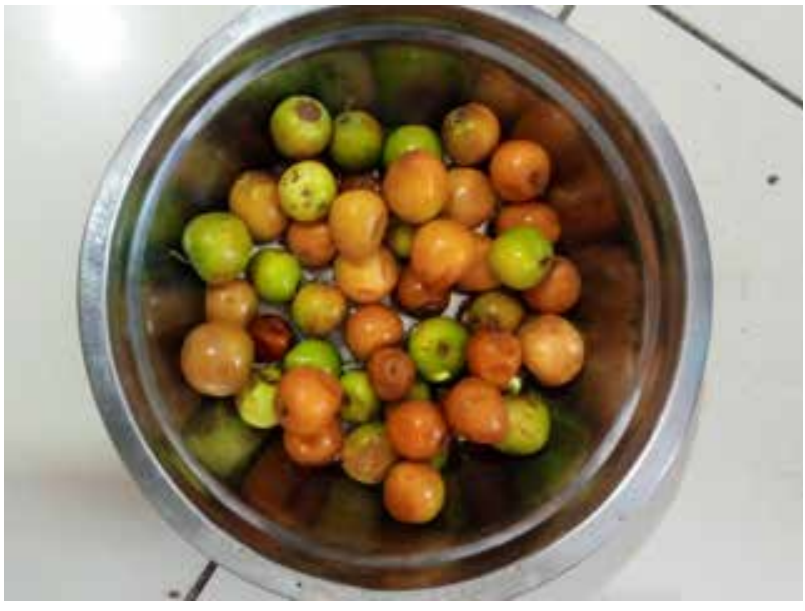

Masau (Ziziphus mauritania)

Photo: Lubomba Bwembelo/CIFOR

While the forest sector needs to pay more attention to these foods, so does the nutrition community. Wild foods are often missing in national dietary-based guidelines and in food composition tables. Food composition tables record the amounts of nutrients found in individual foods that are commonly consumed in a country (or region) to enable nutritionists to understand how particular foods contribute to meeting nutrient requirements. Many of the wild foods that were consumed in the study sites do not appear in the Zambian Food Composition Table, and for the few that that do appear, information on key nutrients is missing. This is true for many wild foods globally. The FAO/INFOODS Food Composition Database for Biodiversity compiles existing composition values for wild foods from all over the world, but is missing information on vitamins for most of these foods, which is arguably the most relevant category of nutrients from fruits (FAO 2019).

\section{Recommendations}

1. Collect data on the quantities of wild foods collected and consumed nationally. Elements of data collection could be incorporated into standard national dietary and forestry surveys.

2. Given the large regional variation in collection patterns, surveys need to: (i) be widely distributed nationally; and (ii) allow for the variable and non-standard sizes of household measuring units.

3. Food composition data for wild foods should be collected and reported in national food composition tables in order to enable researchers to understand the contributions that these foods make to dietary intake of essential nutrients.

4. Widely collected and consumed, wild foods can be of enormous benefit to food and nutrition security; therefore, the nutritional value of wild foods from forests should be factored into land-use and forest management decision making. 


\section{Acknowledgments}

The authors would like to thank Sven Walters, Ewald Rametsteiner, Jody Harris, Julie Bélanger, Mulia Nurhasan, and James Reed for their excellent comments and suggestions. We also thank Agus Maulana for creating the map in Figure 1. This work was the result of a collaboration between the Food and Agricultural Organization (FAO) of the United Nations and the Center for International Forestry Research. The project also received support from the USAID's Forest and Biodiversity Bureau. This work forms part of the CGIAR's Forests, Trees, and Agroforestry research program.

\section{References}

Afshin A, Sur PJ, Fay KA, Cornaby L, Ferrara G, Salama JS, Mullany EC, Hassen Abate K, Abbafati C, Abebe Z et al. 2019. Health effects of dietary risks in 195 countries, 1990-2017: A systematic analysis for the Global Burden of Disease Study 2017. Lancet 393:1958-1972.

BBC. 2019. Why Africa should 'stop eating one of its favourite foods'. Accessed 25 March 2021. https://www. bbc.co.uk/news/world-africa-49714037

Bélanger J and Pilling D, eds. 2019. The State of the World's Biodiversity for Food and Agriculture. FAO Commission on Genetic Resources for Food and Agriculture Assessments. Rome: Food and Agriculture Organization (FAO). 572. http://www.fao.org/3/CA3129EN/CA3129EN.pdf Berners-Lee M, Kennelly C, Watson R and Hewitt C. 2018. Current global food production is sufficient to meet human nutritional needs in 2050 provided there is radical societal adaptation. Elementa: Science of the Anthropocene 6: 52. https://doi.org/10.1525/elementa. 310.f1

Harris J, Chisanga B, Drimie S and Kennedy G. 2019.

Nutrition transition in Zambia: Changing food supply, food prices, household consumption, diet and nutrition outcomes. Food Security 11:371-387. https://doi. org/10.1007/s12571-019-00903-4

Ickowitz A, Powell B, Salim MA and Sunderland T. 2014. Dietary quality and tree cover in Africa. Global Environmental Change 24: 287-294. https://doi. org/10.1016/j.gloenvcha.2013.12.001

[FAO] Food and Agriculture Organization. 2016. Integrated land use assessment phase II - Report for Zambia. Lusaka, Zambia: FAO and the Forestry Department, Ministry of Lands and Natural Resources.

Mason-D'Croz D, Bogard J, Sulser T, Cenacchi N, Dunston S, Herrero M and Wiebe K. 2019. Gaps between fruit and vegetable production, demand, and recommended consumption at global and national levels: An integrated modelling study. The Lancet. Planetary Health 3(7):e318-29.

Rowland D, Ickowitz A, Powell B, Nasi R and Sunderland T. 2017. Forest foods and healthy diets: Quantifying the contributions. Environmental Conservation 44(2):102- 114

Sorrenti S. 2017. Non-wood forest products in international statistical systems. Non-wood forest products series no. 22. Rome: FAO.

[WHO and FAO] World Health Organization and Food and Agriculture Organization. 2002. Diet, nutrition and the prevention of chronic diseases. World Health Organization Technical Report Series. 916: i-viii.

Willett W. et al. 2019. Food in the Anthropocene: The EATLancet commission on healthy diets from sustainable food systems. Lancet 393:447-492.

Some rights reserved. This work is available under a CC BY-NC-SA 3.0 IGO licence

\begin{tabular}{|c|c|c|}
\hline (2) & $\begin{array}{l}\text { RESEARCH } \\
\text { PROGRAM ON } \\
\text { Forests, Trees and } \\
\text { Agroforestry }\end{array}$ & $\begin{array}{l}\text { The CGIAR Research Program on Forests, Trees and Agroforestry (FTA) is the world's largest research for } \\
\text { development program to enhance the role of forests, trees and agroforestry in sustainable development } \\
\text { and food security and to address climate change. CIFOR leads FTA in partnership with ICRAF, the Alliance } \\
\text { of Bioversity International and CIAT, CATIE, CIRAD, INBAR and TBI. }\end{array}$ \\
\hline & & FTA's work is supported by the CGIAR Trust Fund: cgiar.org/funders/ \\
\hline
\end{tabular}

\section{USAID}

